\title{
Narratives as social practice in organisational contexts
}

\author{
Dorien Van De Mieroop, Jonathan Clifton and \\ Stephanie Schnurr \\ KU Leuven | Université Polytechnique Hauts-de-France \\ University of Warwick
}

Organizational studies, as a discipline, has displayed a strong interest in the use of narrative analysis to investigate issues of concern to scholars, such as those around sense-making, communication, politics and power, learning and change, as well as identity and identification (Rhodes \& Brown, 2005). However, much, though of course not all, of this research has tended to focus on 'big' stories i.e., "those derived from interviews, clinical encounters, autobiographical writing, and other such interrogative venues" (Freeman, 2006, p.131) - and has paid little attention to small stories - i.e., "those derived from everyday social exchanges" (Freeman, 2006, p.131; see also Georgakopoulou, 2006). Moreover, these 'big' stories are often analysed as decontextualized end-products (the outcome). Consequently, the fine-grained detail of the exact formulation of stories (the medium), which necessarily has an impact on the narrative as product, is often overlooked. Furthermore, other aspects of the storytelling activity, such as the extent to which narratives are told in collaboration with others - ranging from interviewers for 'big' stories to co-tellers for 'small' stories - and questions around why particular narratives are told at one particular point in time and place rather than at another tend to receive much less attention (though see Clifton et al., 2020). Yet, we argue that these aspects of storytelling are particularly deserving of academic attention. This is because they enable researchers to obtain a much more multi-facetted insight into how narratives are produced and how they work in the specific context in which they occur. This is exactly what a narrative as social practiceapproach capitalizes on, namely the actual in situ telling of the stories (De Fina \& Georgakopoulou, 2008). It has a clear emphasis on the analysis of stories as sequentially organized dialogic constructions which are embedded in the local business of the storytellers and which are rhetorically and recipient designed to 'do things' such as blaming, accounting for action, building acceptable moral identities, and so on. 
Moreover, whilst analysing storytelling as social practice has "a focus on local interaction as a starting point for analysis” (De Fina \& Georgakopoulou, 2015, p.3), it does not restrict itself to the analysis of storytelling talk. As De Fina and Georgakopoulou (2015, p.3) maintain, it also seeks "an understanding of the embedding of narratives within discursive and sociocultural contexts" and so it is concerned with the interplay between discourse little-d (i.e., language in use, cf. Gee, 1999) and Discourse big-D (i.e., the wider socio-historical context of storytelling, cf. Gee, 1999). While the focus on 'little d'-discourse invites a careful scrutiny of the particularities that characterize the formulation of these stories, often in collaboration - or, alternatively, in contestation - with other interlocutors, the focus on Discourse 'big-D' takes into account aspects of the contexts beyond those in which the stories are told. Given the focus of this special issue on narratives in organizational contexts, the contexts that can typically be made relevant in these storytelling activities, range from the highly specific and local (e.g. at the level of the Community of Practice, Wenger, 1988) through the more abstract level of organizational missions and values to larger sociocultural contexts that are characterized by big D-Discourses, or as they are alternatively called, 'dominant discourses' or 'master narratives' (Bamberg, 2005). Whilst these may be considered to be "pre-existent sociocultural forms of interpretation" (Bamberg, 2005, p. 287), nevertheless they are always negotiated through interaction during which storytellers selectively draw upon particularized versions of these Discourses (Clifton \& Van De Mieroop, 2016). In other words, Discourses provide resources that storytellers draw upon in the here-and-now of the telling which, when drawn upon, are reflexively (re)enacted in the storytelling talk. Thus, there is a constant oscillation and interplay between language use, the contexts in which this occurs, and wider socio-historical ways of understanding the world.

The papers in this special issue explore a wide range of story types - both big and small - and they range across various genres (Van De Mieroop, 2021), which implies that the stories may sometimes deviate significantly from the canonical narrative of personal experience as proposed in the seminal work by Labov and Waletzky (1966). Although the papers in this collection focus on different aspects of organisational realities and practices, each contribution essentially draws on naturally-occurring stories told in or about the workplace and they come from a number of different venues: business meetings, professional-lay encounters, physician-patient/physician interactions, online posts, mentoring sessions, informal workplace talk about work, and so on. Moreover, exploring different organisational contexts - including healthcare, further education, business, non-profit organisations, and organisational training - the papers use different approaches to narratives - such as interactional sociolinguistics, positioning theory, membership categorization analysis, ethnography, and conversation analysis. 
Despite this variety of genres, approaches to analysis, and contexts, the following leitmotiv emerges from the papers in this special issue, namely that these narratives are clearly multifunctional social practices. Of course, many of these narratives serve the more general purpose of making sense of everyday events in the narrator's life. It is therefore not surprising that in many contributions to this special issue we can observe that the narratives are topically related to some form of contestation or negative evaluation (see especially the contributions of Brookes et al., Chalupnik, Jacobs et al., and Nissi \& Pässilä). In these cases, different viewpoints, opinions, and arguments emerge and are played out against one another. This negotiation of meaning occurs either in real-time in situ narratives, or it is dealt with through post-hoc narratives that attempt to capture and understand what happened. Beyond sensemaking, the articles in this issue attest to the plethora of functions that these narratives may simultaneously serve. While some of these functions are clearly oriented to the more transactional nature of telling stories in workplace contexts (e.g., managing disagreement; sharing knowledge; displaying expertise; making decisions; establishing protocols and jointly solving problems), other functions are more relationally oriented, (e.g., reinforcing trust, negotiating blame, and empowering employees). In this way, narratives may contribute to the construction of a variety of work- and non-work-related identities, ranging from expert identities through in-group identities, to migrant identities. Hence these multifunctional narratives may also constitute an integral part of personal as well as professional development.

Furthermore, all contributions explore how these narratives draw on, and so (re)enact, the contextual 'layer(s)' in which they occur. 'Context' is a multi-layered concept, and while it is thus possible that narrators make relevant a multiplicity of contextual layers in the stories they tell, often the exploration of the relation between narratives and 'only' one or two contextual layers is capitalized on. This is also the case for the narratives that the contributions to this special issue focus on, and we have used this contextual orientation as an ordering principle for the compilation of this issue. In particular, we start with contributions in which the narrative's relation to local contexts is explored, and we gradually shift to narratives in which an increasingly 'larger' societal orientation is made relevant. Thus, we start with three papers that mainly scrutinize the formulation of these narratives vis-à-vis the specificities, constraints and affordances of the local contexts in which they occur. In particular, the paper by Gavin Brookes, Tony McEnery, Mark McGlashan, Gillian Smith and Mark Wilkinson explores narratives as social practice in the online context of the National Health Service in England. Drawing on corpus analysis and using Labov and Waletzky's (1966) framework, the authors analyse the discursive strategies through which patients use narratives to evaluate their experiences of healthcare services online. Findings illustrate not only that 
narratives frequently occur in this context, but that they occur particularly often in comments that negatively evaluate care. Moreover, as mediated social practice, the narratives are shaped by the technological affordances and social dynamics of this online context.

Another paper that focuses on narratives as social practice on the local level within a medical context is Amy Fioramonte's contribution. Her paper explores the use of small stories told by physicians and patients in the various phases of face-to-face medical interviews. An in-depth analysis of audio-recorded interactions at two outpatient clinics in the US illustrates that narrative accounts are interwoven and unfold across various phases of the medical interview and are utilized in a variety of ways to collaboratively accomplish specific social practices, such as raising difficult topics, resisting treatment, and influencing the treatment decision making process.

The final paper that particularly zooms in on the local ecology of storytelling is the paper by Malgorzata Chalupnik. More specifically, she focuses on story ownership and tellership, i.e., who owns a story and who has the right to tell it (and how). Conducting an in-depth analysis of authentic workplace interactions involving the members of an IT team at a Further Education institution in the UK, this paper unpacks the specific processes through which story tellers collaboratively - but not necessarily harmoniously - tell a story. Particular attention is paid to the negotiation of meaning that becomes visible in the often incomplete and fragmented narratives, and the important role of the ecology of storytelling including the audience (who can become a co-narrator) and the setting of the storytelling (i.e., the workplace).

Then three other papers are presented in which the embedding of stories within the particular locally enacted Community of Practice is highlighted.

A first contribution relating to this contextual level is Almut Koester's article on story-telling that emerges in a care home for older people with dementia in England. In particular, she zooms in on interactions of the care staff and teases out the functions that narratives perform in the staff's workplace practice and more generally in that of the care home. Focusing specifically on transactionally oriented stories, Koester finds that these stories provide key sites for identity construction, relationship-building, sense-making, knowledge-sharing, joint problem-solving and (critical) reflection on and evaluation of the care home practices. In this way, narratives are crucial to ensuring that the work of the care home runs smoothly and that residents receive appropriate and professional care.

Also drawing on data from within a medical context, Mariana LazzaroSalazar analyses the use of case narratives during staff meetings in a New Zealand healthcare institution. From a methodological perspective, she combines the notion of Communities of Practice with interactional sociolinguistics. Making the 
link between the professional practice of evidenced based medicine and narrative as social practice, she focuses on the way in which narratives are negotiated by the participants and are used to: manage disagreement; attribute accountability; share knowledge; display expertise; make-decisions; and establish protocols. Narratives are thus shown to be an integral part of reflective practice in and through which health care professionals expand their skills, knowledge, and expertise and so manage the medical practices of the team.

Christina Efthymiadou and Jo Angouri also use this combination of an interactional sociolinguistic approach and the notion of Communities of Practice, but focus on a rather different context. More specifically, they analyse an iterative narrative of the founding of a Greco-Turkish business partnership as it emerges in different contexts. Significantly, whilst historically Greco-Turkish relationships have often been strained, in their analyses, Efthymiadou and Angouri demonstrate how the storytellers draw on the participants' common heritage as Pontics from the Black Sea region of modern Turkey. The repeated telling of the founding narrative, and the evocation of a common heritage, allows the key organisational players to establish an in-group identity that reinforces trust between the partners and which is conducive to the smooth running of the partnership.

Following this, there are two papers that tease out the ways in which narratives can be reflexively related to the more abstract organizational level. First, Riikka Nissi and Anne Pässilä use conversation analysis to investigate stories told during mentoring sessions for trainee consultants in Finland. They find that interaction in the mentoring sessions often takes the form of narratives of the trainee's experiences as they reflect upon their practice and their professional development. Nissi and Pässilä particularly focus on contested narratives in which the participants produce different narratives of the same event as they negotiate blame and accountability for a problematic intervention by trainees. Through the analysis of these emergent narratives-in-interaction, they demonstrate how narratives are an integral part of professional development and how they become a vehicle for reflection that shapes professional identities, competences, and practices.

Next, an entirely different context for 'narrative work' is focused upon in Leigh Harrington's article on telephone-mediated debt collection encounters. Unlike other professional-lay encounters, debt collection typically entails "imposition" by organisational representatives on their clients in order to recover owed money. Importantly, in this case the professional represents a credit union, i.e., a small, non-profit organisation that provides fair and ethical financial services, including savings and loans, to the local community. Harrington argues that the organisation's values are made tangible in the narrative practices during these collection encounters, in which the collector affords indebted individuals interactive 
space and agency to tell their stories. In this way, the debt collector foregrounds concern for their personal problems over their debt and so enacts the organisation's consciously ethical, responsible, and debtor-centric principles.

The two final contributions then specifically tap into the way these stories interact with the larger societal context and big D-Discourses. First, Catho Jacobs, Dorien Van De Mieroop and Colette Van Laar investigate the ways in which narratives are used to make sense of (contested) past experiences. Using positioning theory and drawing on membership categorization analysis, their paper illustrates how storytellers with migrant backgrounds in Flanders tell stories of micro-aggressions in institutional and workplace contexts that project powerless and outgroup ethnic identities on them. However, in the here and now of the storytelling, the storytellers not only (re)construct in-group identities between tellers but they also (re)claim empowered identities in the storyworld. The distinctiveness of this paper is that it demonstrates how analysing narratives as social practice can provide empirical evidence that complements social psychological models of rejection/identification that to date have only been investigated in laboratory-based contexts and which have not been researched as in situ social practices.

In the final paper of this special issue, Michael Handford conducts a corpusassisted discourse analysis of national stereotypes that occurred in authentic business meetings in a range of different workplaces in Europe, Asia and the US. Findings show that the national stereotypes that are used in workplace narratives constitute a contextual, situated social practice. After categorising the stereotypes that occur in the meetings, this paper discusses the roles they play in indexing the identities of the stereotyped and the stereotyping. It is argued that while the use of national stereotypes may be ethically problematic and potentially detrimental to business success, their use may be motivated by local workplace goals. In this way, this final contribution to the special issue nicely links the local contextual level to larger societal ideologies and Discourses.

Overall, we hope that this special issue thus offers an overview of the various contextual layers that can be made relevant in stories occurring in organizational contexts, while, as the individual contributions show, also paying attention to the often multi-layered contextual orientation of storytelling activities. In this way, this issue specifically aims to foreground the link between highly particular stories about the everyday business of living and working - what these events mean and $d o$ - and the way in which they may affect local, organizational and more global processes of living and working on a more general level. Moreover, the various contributions clearly demonstrate the wide variety of functions that narratives can perform in - and in relation to - the workplace, thus clearly emphasizing the importance of storytelling for organizational life. Taken together, the 
contributions in this special issue thus illustrate some of the many benefits that approaching narratives in organisational contexts from a social practice perspective can bring.

\section{Funding}

Open Access publication of this article was funded through a Transformative Agreement with KU Leuven.

\section{References}

Bamberg, M. (2005). Master Narratives. In D. Herman, M. Jahn, \& M.-L. Ryan. (Eds.), The Routledge encyclopedia of narrative theory (pp. 287-288). Routledge.

Clifton, J., Schnurr, S., \& Van De Mieroop, D. (2020). The Language of Leadership Narratives: A Social Practice Perspective. Routledge.

Clifton, J., \& Van De Mieroop, D. (2016). Master Narratives, Identities, and the Stories of Former Slaves. John Benjamins. https://doi.org/10.1075/sin.22

De Fina, A., \& Georgakopoulou, A. (2008). Analysing narratives as practices. Qualitative Research, 8(3), 379-387. https://doi.org/10.1177/1468794106093634

De Fina, A., \& Georgakopoulou, A. (2015). Introduction. In A. De Fina \& A. Georgakopoulou. (Eds.), The Handbook of Narrative Analysis (pp. 1-17). Wiley Blackwell. https://doi.org/10.1002/9781118458204.cho

Freeman, M. (2006). Life "on holiday"? In defense of big stories. Narrative Inquiry, 16(1), 131-138. https://doi.org/10.1075/ni.16.1.17fre

Gee, J.P. (1999). An introduction to discourse analysis: Theory and method. Routledge.

Georgakopoulou, A. (2006). Thinking big with small stories in narrative and identity analysis. Narrative Inquiry, 16(1), 122-130. https://doi.org/10.1075/ni.16.1.16geo

Labov, W., \& Waletzky, J. (1966). Narrative Analysis: oral versions of personal experience. In J. Helm. (Ed.), Essays on the Verbal and Visual Arts (pp. 12-44). Universiy of Washington Press.

Rhodes, C., \& Brown, A.D. (2005). Narrative, organizations and research. International Journal of Management Reviews, 7(3), 167-188. https://doi.org/10.1111/j.1468-2370.2005.00112.x

Van De Mieroop, D. (2021). The Narrative Dimensions Model and an Exploration of Various Narrative Genres. Narrative Inquiry, 31(1), 4-27. https://doi.org/10.1075/ni.19069.van Wenger, E. (1988). Communities of practice: Learning, meaning and identity. Cambridge University Press. 


\section{Address for correspondence}

Dorien Van De Mieroop

Faculty of Arts

KU Leuven

Blijde-Inkomststraat 21

P.O. box 3308

B-30oo Leuven

Belgium

dorien.vandemieroop@kuleuven.be

(iD) https://orcid.org/oooo-0002-1704-2165

\section{Co-author information}

Jonathan Clifton

Université Polytechnique Hauts-de-France

jonathan.clifton@uphf.fr

(iD) https://orcid.org/oooo-0oo2-4788-4726
Stephanie Schnurr

Department of Applied Linguistics

University of Warwick

s.schnurr@warwick.ac.uk

(iD) https://orcid.org/oooo-0003-4072-0726 